Article

\title{
Formulation of New Baking (+)-Catechin Based Leavening Agents: Effects on Rheology, Sensory and Antioxidant Features during Muffin Preparation
}

\author{
Gabriele Carullo ${ }^{1,2}{ }^{-}$, Francesca Scarpelli ${ }^{3}$, Emilia Lucia Belsito ${ }^{2}$, Paolino Caputo ${ }^{3}{ }^{(D)}$, \\ Cesare Oliviero Rossi ${ }^{3}(\mathbb{D})$, Antonio Mincione ${ }^{4}\left(\mathbb{D}\right.$, Antonella Leggio ${ }^{2}\left(\mathbb{D}\right.$, Alessandra Crispini $^{3}$, \\ Donatella Restuccia $^{2, *(\mathbb{D}}$, Umile Gianfranco Spizzirri ${ }^{2} \mathbb{D}$ and Francesca Aiello ${ }^{2}$ (D) \\ 1 Department of Biotechnology, Chemistry and Pharmacy, Department of Excellence 2018-2022, \\ University of Siena, Via Aldo Moro 2, 53100 Siena, Italy; gabriele.carullo@unisi.it \\ 2 Department of Pharmacy, Health and Nutritional Sciences, Department of Excellence 2018-2022, \\ University of Calabria, Edificio Polifunzionale, 87036 Rende, Italy; emilialucia.belsito@unical.it (E.L.B.); \\ antonella.leggio@unical.it (A.L.); umile_gianfranco.spizzirri@unical.it (U.G.S.); \\ francesca.aiello@unical.it (F.A.) \\ 3 Department of Chemistry and Chemical Technologies, University of Calabria, \\ 87036 Arcavacata di Rende-Cosenza, Italy; francesca.scarpelli@unical.it (F.S.); \\ paolino.caputo@unical.it (P.C.); cesare.oliviero@unical.it (C.O.R.); alessandra.crispini@unical.it (A.C.) \\ 4 AGRARIA Department, Mediterranean University of Reggio Calabria, Loc. Feo di Vito, \\ 89122 Reggio Calabria, Italy; amincione@unirc.it \\ * Correspondence: donatella.restuccia@unical.it; Tel.: +39-0984493066
}

Received: 2 October 2020; Accepted: 24 October 2020; Published: 29 October 2020

\begin{abstract}
The aim of this investigation was to prepare two solid mixtures containing a soluble polymorph of (+)-catechin and mucic (MUC) or tartaric (TAR) acids as new leavening agents. The solid mixtures were based on a polymorph of (+)-catechin, characterized through Powder X-ray Diffraction (PXRD) analysis and assayed in in vitro antioxidant and solubility assays. The dough samples were studied by dynamic rheological tests, while muffins were studied through Headspace Solid-Phase Microextraction (HS-SPME)/Gas Chromatography-Mass Spectrometry (GC-MS) analysis to identify volatile compounds, in vitro tests to evaluate antioxidant properties, and sensory analyses. TAR powder showed a solubility in water almost one order of magnitude increased with respect to commercial (+)-catechin (40.0 against $\left.4.6 \mathrm{mg} \mathrm{mL}^{-1}\right)$ and increased antioxidant performances. In particular, TAR showed total phenolic content (TPC) and total antioxidant capacity (TAC) values of $0.0298 \pm 0.021$ and $0.0081 \pm 0.0009 \mathrm{meq} \mathrm{CT} / \mathrm{g}$, while MUC showed better results in terms of 2,2-diphenyl-1-picrylhydrazyl) acid (DPPH) and 2,2'-azino-bis (3-ethylbenzothiazoline-6-sulphonic acid (ABTS), $0.518 \pm 0.015$ and $0.112 \pm 0.010 \mathrm{mg} / \mathrm{mL}$, respectively. MS analysis identified different compounds derived from the lipid oxidation process. Muffins obtained using both powders showed interesting outcomes regarding dough process and appreciable appearance/olfactory/taste/texture profiles. Muffins obtained from TAR-based mixture showed also a total phenolic content of $0.00175 \mathrm{meq} \mathrm{CT} / \mathrm{g}$ muffin, and almost two times improved TAC and scavenger activity against DPPH radical. The formulated powders could be used as suitable health-promoting ingredients in the food industry.
\end{abstract}

Keywords: muffin; baking powder; formulation and characterization; rheology; antioxidant performances; sensory properties; (+)-catechin 


\section{Introduction}

Baked products are widely consumed worldwide. Among them, muffins rank third in breakfast products as they are highly appreciated for their texture and taste [1]. Basic ingredients for muffin production are wheat flour, sugar, milk, fat, and egg added with a leavening agent to drive the baking process. The latter is probably the key factor to obtain a valuable product, producing heat and mass transfer supported by temperature rising and gas production (i.e., $\mathrm{CO}_{2}$ ). The high temperature also induces the formation of a dry surface crust as well as many chemical and physical reactions converting the cake batter into an expanded volume crumb with positive organoleptic features [2].

Many parameters affect the baking process, including ingredient proportion and handling, time, temperature, heating systems, and delivery, as well as the leavening additive employed. In particular, the latter aspect shows dramatic effects on sensory, rheological, and textural features of the final product [3]. Among leavening agents, baking powders are widely used in muffin preparation. Commercial formulations are generally a mixture of inorganic compounds (baking soda and acid salts) that react in presence of moisture and heat to release $\mathrm{CO}_{2}$. Starch is usually added for stability and moisture control. Baking powders differ from one another in relation to diverse acidic constituents. Most of the common acid components are phosphate salts, showing the drawback of negatively affecting the flavor of the final product [4]. Moreover, although phosphates are normal constituents in the body and are regular components of the diet, a re-evaluation of the safety of phosphates-based food additives (E 338-341, E 343, and E 450-452) has been recently conducted by the European Food Safety Authority (EFSA), leading to a final scientific opinion [5]. The EFSA Panel on Food Additives and Flavorings, proposed a group Acceptable Daily Intake (ADI) for phosphates of $40 \mathrm{mg} \mathrm{kg}^{-1} \mathrm{bw}$ per day expressed as phosphorus (P), suitable for healthy individuals, although not enforceable to humans with moderate to severe reduction in renal function (about $10 \%$ of the population). Moreover, based on analytical data, the Panel underlined that $\mathrm{P}$ dietary exposure exceeded the proposed ADI for infants, toddlers, and children at the mean level and for infants, toddlers, children, and adolescents at the 95th percentile; the same conclusion was drawn for food supplements. It follows that, considering the wide diffusion of baked products, replacing phosphates with different leavening ingredients could limit $P$ dietary exposure for better meeting the EFSA proposed dietary intake.

For a further improving of muffins' nutritional value, fortification with polyphenols could be also considered a valuable approach as these compounds have been widely recognized to elicit many health-promoting effects [6]. Flavonoids addition was exploited in the food sector [7-11], also showing in baked products an important antiglycation activity [12,13]. However, flavan-3-ols suffer poor oral bioavailability, implying too high plasma concentrations needed to bring out an assessable impact on health [14]. Several strategies can be adopted to enhance solubility and hence bioavailability of flavonoids [15]; for example, it has been demonstrated that the use of an absorption enhancer, such as apple pectin, increases the intestinal absorption of quercetin, a poorly soluble flavonoid [16]. Moreover, co-crystallization was proved to be effective and some studies reported the application of co-crystals of polyphenols for food and beverage fortification [17,18]. In addition, phospholipid complexation of flavanols can have a positive impact on their oral absorption [19]. The pharmaceutical industry has often taken advantage of polymorphism as a method to overcome bioavailability issues of poorly soluble active ingredients, since it is generally recognized that different polymorphic forms of a chemical compound can display different physicochemical properties; in particular, water-solubility [20]. Moreover, the conversion of an active ingredient from a polymorphic form to another can be gained through simple experimental methods, such as solvent-crystallization and grinding.

Flavonoids can exist in more crystalline forms [21,22], including solvates and hydrates [23-25]; however, to the best of our knowledge, flavonoids polymorphism has not yet been applied in the field of food and beverage fortification.

On this basis, in this study the (+)-catechin (CT) polymorphism has been exploited in order to prepare two multifunctional solid mixtures, containing a soluble form of $(+)$-catechin $(\mathrm{CT})$ and mucic acid (MA) or tartaric acid (TA) employed as baking ingredients in muffin preparation. 
Catechins are phytochemical compounds found in high concentrations in a variety of plant-based foods and beverages. More precisely, catechin is the 3,3',4',5,7-pentahydroxyflavan with two steric forms. The (+)-catechin was selected due to its exceptional positive effects related to human health. Among these, catechins have function as an anti-angiogenic antitumor agent, modulator of tumour cell response to chemotherapy, and anti-inflammatory action in bowel disease by direct and indirect inhibition of oxidative stress [26-28]. Galactaric acid, also known as mucic acid (MA), is a symmetrical six carbon diacid, used to produce a gum alternative to arabic gum. Currently, MA is commercially produced by oxidation of galactose with nitric acid or from D-galacturonic acid (D-galUA) by electrolytic oxidation. A useful alternative source of D-galUA is pectin, an abundant component in fruit peels that represents an available and inexpensive source for production of MA [29]. Tartaric acid is an important food additive naturally occurring in plants like grapes, apricots, apples, bananas, avocados, and tamarinds. Its salt potassium bitartrate, commonly known as cream of tartar, develops naturally in the process of fermentation. It is usually mixed with sodium bicarbonate to form a baking powder used as a leavening agent in food preparation. TA can exist in different isomeric forms, but only L (+)-tartaric acid and its salts are authorized as food additives labelled as E334. In this context, to valorise catechin health effects and safe use, as well as the sustainable recovery of both acids from agro-food wastes (grape pomace for L (+)-tartaric acid and citrus pectin for MA), we decided to formulate these two new baking powders. In this new baking powder, the acidic counterpart necessary to guarantee the leavening effect, exerted most commonly by calcium acid phosphate, sodium aluminumsulfate were substituted by Tartaric acid and Mucic acid, mixed with alkali (sodium bicarbonate is known commonly as baking soda) and a polymorph of catechin. By adding water to this mixture, a chemical reaction is achieved, producing carbon dioxide, which is trapped in tiny air pockets in the dough or batter.

To the best of our knowledge, this was the first attempt to verify the effectiveness of an alternative leavening agent able, at the same time, to carry on a product fortification. After X-ray characterisation of the multi-functional solid mixtures, their antioxidant features and their effects on batter rheology were investigated, while, to highlight the effect on the quality of the final product, antioxidant activity, flavor compounds and sensory characteristics were evaluated on muffins samples.

\section{Materials and Methods}

\subsection{Chemicals}

(+)-Catechin, ascorbic acid, gallic acid, tartaric acid, mucic acid, sodium hydrogen carbonate, starch, Folin-Ciocalteu reagent, sodium carbonate, sulphuric acid, sodium phosphate, ammonium molybdate, 2,2-diphenyl-1-picrylhydrazyl) acid (DPPH), 2,2'-azino-bis (3-ethylbenzothiazoline-6-sulphonic acid (ABTS), and formic acid were purchased from Sigma-Aldrich (Milford, MA, USA).

n-Hexane, methanol, water, and ethanol 96\% were purchased from Merck (Darmstad, Germany) and VWR International (Milan, Italy) and, unless specified otherwise, were of analytical grade or higher.

\subsection{Synthesis of Baking Powders Through Slurry Process}

In a round-bottom flask, CT (500 mg, $1.72 \mathrm{mmol}$ ) was slurred with TA (129 mg, $0.86 \mathrm{mmol}$ ) or MA (181 mg, $0.86 \mathrm{mmol}$ ) in $5 \mathrm{~mL}$ of ethanol, for $24 \mathrm{~h}$ at room temperature, in a dark atmosphere. The round-bottom flasks were left in the hood undisturbed, and, after two days, two solids were obtained, named CT_TA and CT_MA. To obtain the correspondent baking powders (labelled M_BP and T_BP, respectively) about $800 \mathrm{mg}$ of CT_TA and CT_MA were mixed with $800 \mathrm{mg}$ of sodium hydrogen carbonate and $2.4 \mathrm{~g}$ of starch, in order to obtain $4.0 \mathrm{~g}$ each of the two baking powders.

\subsection{Powder X-ray Diffraction (PXRD) ofCT, $C T \_T A$ and $C T \_M A$}

The PXRD analysis was performed using a Bruker D2-Phaser operating at $30 \mathrm{kV}$ and $10 \mathrm{~mA}$, using $\mathrm{Cu}-\mathrm{K} \alpha$ radiation $(\lambda=1.5418 \AA$ ) and equipped with a Lynxeye detector. The PXRD patterns were 
acquires over an angular range of $5-45^{\circ} 2 \theta$, with a step size of $0.01^{\circ}$. The obtained diffraction profiles were analyzed with DIFFRAC.EVA diffraction software (version 3.1, Bruker AXS 2010-2013, Billerica, MA, USA).

\subsection{Antioxidant Performances of MUC, TAR and COM}

\subsubsection{Total Phenolic Content}

The total phenolic content (TPC) in the synthetic (M_BP and T_BP) and commercial baking powders (C_BP) was detected according to the Folin-Ciocalteu colorimetric method [30,31]. Briefly, a volume of each sample $(6.0 \mathrm{~mL})$ and the Folin-Ciocalteu reagent $(1.0 \mathrm{~mL})$ were mixed and, after $3 \mathrm{~min}, 3.0 \mathrm{~mL}$ of $\mathrm{Na}_{2} \mathrm{CO}_{3}(5.0 \% \mathrm{w} / \mathrm{v})$ was added. Positive control and blank solutions was also prepared by substituting the sample with the same volume of $0.1 \%(w / v)$ ascorbic acid and hydro alcoholic solution (50:50 v/v), respectively. The absorbance value of each solution was recorded after $2 \mathrm{~h}$ under stirring at $760 \mathrm{~nm}$ by a Jasco V-530 UV/VIS Spectrometer (Jasco, Tokyo, Japan). The TPC was expressed as milliequivalent of CT per g of baking. A calibration curve was recorded by six gallic acid standard solutions. Each solution $(6.0 \mathrm{~mL})$ was added to the Folin-Ciocalteu reagent to raise the following final concentrations: 5.0, 10.0, $20.0,40.0,60.0$, and $100.0 \times 10^{-6} \mathrm{~mol} \mathrm{~L}^{-1}$. UV-Vis analyses were performed after $120 \mathrm{~min}$ of incubation under stirring and correlation coefficient, slope and intercept of the regression equation obtained by the method of least squares were calculated.

\subsubsection{Determination of Total Antioxidant Capacity}

A literature protocol, with few changes was employed to determine total antioxidant capacity (TAC) of each baking agent [32]. Briefly, an aliquot of hydro-alcoholic solution (50:50 $\mathrm{v} / \mathrm{v})$ of each sample (0.3 mL) (M_BP, T_BP and C_BP) was mixed to $1.2 \mathrm{~mL}$ of reagent solution $\left(0.6 \mathrm{~mol} \mathrm{~L}^{-1} \mathrm{H}_{2} \mathrm{SO}_{4}\right.$, $28.0 \mathrm{~mol} \mathrm{~L}^{-1} \mathrm{Na}_{3} \mathrm{PO}_{4}$, and $\left.4.0 \mathrm{~mol} \mathrm{~L}^{-1}\left(\mathrm{NH}_{4}\right)_{2} \mathrm{MoO}_{4}\right)$ at $95^{\circ} \mathrm{C}$, and after $150 \mathrm{~min}$ the absorbance was recorded at $695 \mathrm{~nm}$. Ascorbic acid $0.1 \%(w / v)$ was used as positive control. The total antioxidant activity of each baking powder was expressed as milliequivalent of CT equivalent per $\mathrm{g}$ of sample. A calibration curve was recorded by six catechin standard solutions. Each solution $(0.3 \mathrm{~mL})$ was added to $1.2 \mathrm{~mL}$ of reagent solution in order to raise the following concentrations: 5.0, 10.0, 20.0, 40.0, 60.0, and $100.0 \times 10^{-6} \mathrm{~mol} \mathrm{~L}^{-1}$. UV-Vis analyses were performed after $150 \mathrm{~min}$ of incubation, and correlation coefficient, slope, and intercept of the regression equation obtained by the method of least squares were calculated.

\subsubsection{Determination of Scavenging Activity on DPPH Radicals}

Baking agents (M_BP, T_BP and C_BP) scavenger activities towards DPPH radical were evaluated following a literature protocol with some modifications [33]. Briefly, equivolumetric hydroalcoholic solution of each sample $(1.0 \mathrm{~mL})$, equivolumetric hydroalcoholic mixture $(4.0 \mathrm{~mL})$ and $200 \mu \mathrm{mol} \mathrm{L}^{-1}$ ethanol DPPH solution $(5.0 \mathrm{~mL})$ were mixed in a volumetric flask at $25^{\circ} \mathrm{C}$ and, after $24 \mathrm{~h}$, the absorbance was recorded at $517 \mathrm{~nm}$. Ascorbic acid $0.1 \%(w / v)$ was used as positive control. Scavenging properties of the tested matrices were expressed as $\mathrm{IC}_{50}$ (the concentration of sample that causes a $50 \%$ decrease in the starting DPPH concentration).

\subsubsection{Determination of Scavenging Effect on the ABTS Radical Cation}

Baking agents (M_BP, T_BP and C_BP) scavenging properties were evaluated in aqueous media towards ABTS radical [34]. In a general procedure, $500 \mu \mathrm{L}$ of hydroalcoholic solution (50:50 v/v) on each baking powder were added to $2.0 \mathrm{~mL}$ of the $\mathrm{ABTS}^{+}$radical solution $\left(7.0 \mathrm{mmol} \mathrm{L}^{-1}\right.$ properly diluted to raise approximately an absorbance of 0.70 at $734 \mathrm{~nm}$ ). The mixture was incubated at $37^{\circ} \mathrm{C}$ for $5 \mathrm{~min}$ and the absorbance was recorded at $734 \mathrm{~nm}$. A positive control based on an ascorbic acid $0.1 \%(w / v)$ solution was employed. The absorbance decrease of the ABTS radical cation provided the 
antioxidant activity of the baking powders, expressed as $\mathrm{IC}_{50}$ (the concentration of sample that causes a $50 \%$ decrease in the starting ABTS concentration).

\subsection{Preparation of Muffins}

Ingredients: 1 egg (M measure, AIA), partially skimmed milk UHT(Parmalat) (100 g), white sugar Eridania(100 g), 00 wheat flour Barilla(100 g), sunflower oil Carapelli $(100 \mathrm{~g})$ and $4 \mathrm{~g}$ of M_BP, T_BP or $8 \mathrm{~g}$ of C_BP Lievito PaneAngeli.

Method: the egg was manually brought with a whisk into a glass bowl, sugar was added and the mixture was beaten until a clear and frothy consistency is reached. Then, the oil was added to the mixture. In another bowl, baking and wheat flour were mixed, sifted, and gradually this mixture was added to the dough. Finally, milk was added. Into twelve compartments of a sanitized aluminum muffin pan (each chamber: $5.0 \mathrm{~cm}$ top diameters, $5.0 \mathrm{~cm}$ bottom, $4.0 \mathrm{~cm}$ height) about $40.0 \pm 0.5 \mathrm{~g}$ of muffin butter were placed. They were cooked in a preheated domestic oven REX ${ }^{\circledR}$ Electrolux under static mode of the oven at $180^{\circ} \mathrm{C}$ for $25-30 \mathrm{~min}$ to obtain the corresponding muffins labelled as M_MUF, T_MUF, and C_MUF (Figure 1).

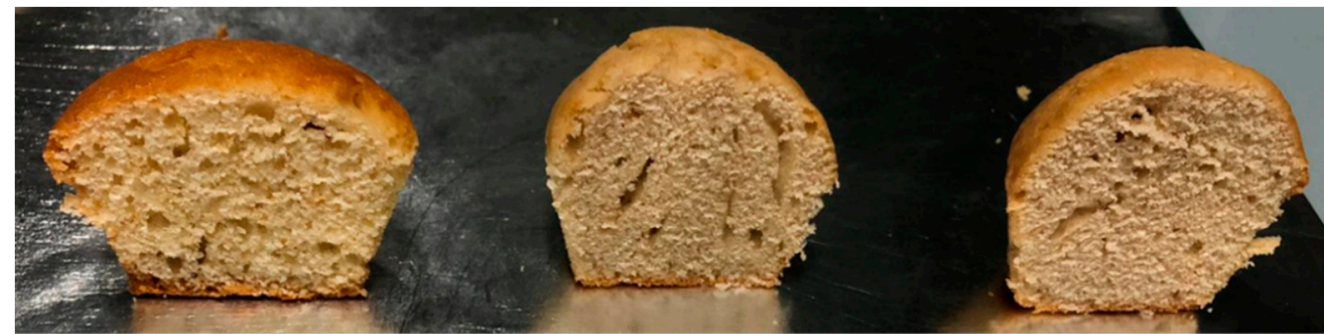

C_MUF

M_MUF

T_MUF

Figure 1. Representative samples of muffins obtained using the new leavening agents (M_MUF, T_MUF and commercial one C_MUF).C_MUF = Muffin prepared by C_BP; M_MUF = Muffin prepared by M_BP; T_MUF = Muffin prepared by T_BP.

\subsection{Rheological Measurements}

Rheological measurements were done using a shear strain-controlled rheometer RFS III (Rheometrics, Piscataway, NJ, USA) equipped with a parallel plate geometry (gap $2.0 \pm 0.1 \mathrm{~mm}$, diameter $50 \mathrm{~mm}$ for the samples analyzed within the temperature range $15-25^{\circ} \mathrm{C}$ ) and a Peltier system $\left( \pm 0.1^{\circ} \mathrm{C}\right)$ for temperature regulation. Transient experiments yielded steady flow experiment results, according to step-rate tests where the viscosity was measured at different shear rate values in the set time. The small amplitude dynamic tests (frequency sweep tests) provided information on the linear viscoelastic behaviour of materials through the determination of the complex shear modulus (Equation (1))

$$
G^{*}(\omega)=G^{\prime}(\omega)+i G^{\prime \prime}(\omega)
$$

where the complex modulus $\left(G^{*}\right)$, represents a quantitative measure of material stiffness or resistance to deformation, $G^{\prime}(\omega)$ represents a measure of the reversible, elastic energy, while $G^{\prime \prime}(\omega)$ stands for the irreversible viscous dissipation of the mechanical energy and $i$ is the imaginary unit of the complex number $[35,36]$. The applied strain amplitude for the viscoelastic measurements was reduced until the linear response regime was reached. This analysis was done by carrying out strain sweep tests in all investigated temperature ranges [37].

\subsection{Antioxidant Performances of Muffin}

Antioxidant properties of muffins were evaluated by performing polyphenol extraction procedure reported in literature with some modification [38]. Five grams of each muffin (M_MUF, T_MUF and 
C_MUF) were accurately weighed and defatted with $n$-hexane $\left(150 \mathrm{~mL}, 20 \mathrm{~min}, 70^{\circ} \mathrm{C}\right)$. The n-hexane fraction was decanted and the defatted sample was extracted in $40 \mathrm{~mL}$ of a mixture $(70 \%$ methanol, $29.7 \%$ water, and $0.3 \%$ formic acid), at $70{ }^{\circ} \mathrm{C}$ for $45 \mathrm{~min}$ under stirring, and then filtered, evaporated, and finally dried under vacuum until constant weight.

TPC and antioxidant performances of the muffins' extracts were performed following the procedures previously reported. Specifically, TPC and TAC were expressed as milligram of CT per gram of muffin, while scavenger activities in organic and aqueous environments were evaluated as $\mathrm{IC}_{50}$ values.

\subsection{Extraction of Volatile Compounds from Muffins by Headspace Solid-Phase Microextraction (HS-SPME)}

For HS-SPME analysis, a $10 \mathrm{~mL}$ vial containing a fixed amount $(2.5 \mathrm{~g})$ of each type of freshly baked muffin was sealed with a PTFE/silicone septum and heated in a $30{ }^{\circ} \mathrm{C}$ thermostatic water bath for $30 \mathrm{~min}$. Once thermal equilibrium had been attained, a 50/30 $\mu \mathrm{m}$ DVB/CAR/PDMS (divinylbenzene/carboxen/polydimethylsiloxane) SPME fiber was used to sample the headspace above the solid matrix. DVB/CAR/PDMS coating is a polymeric multiphase containing both absorbing (PDMS) and adsorbing (DVB and CAR) phases able to trap polar and non-polar compounds. Headspace sampling was conducted for $3 \mathrm{~h}$ at $30^{\circ} \mathrm{C}$. After this time, the analytes on the fiber were thermally desorbed for $10 \mathrm{~min}$ at $250^{\circ} \mathrm{C}$ in the injector of the Gas Chromatography -Mass Spectrometry (GC-MS) system, then they were separated and identified. Prior to use, the fibers were thermally conditioned in the GC injector according to manufacturer's instructions. The thermal equilibrium time was optimized monitoring from 15 to $60 \mathrm{~min}$ the extraction efficiency, using a constant extraction time of $15 \mathrm{~min}$. After $30 \mathrm{~min}$ a relatively constant response was observed up to $60 \mathrm{~min}$. Therefore, $30 \mathrm{~min}$ was chosen as thermal equilibrium time. Headspace sampling and related GC/MS analysis were performed in triplicate for each sample type.

\subsection{GC-MS Analyses}

The analyses were carried out on an Agilent GC/MS system consisting of a 6890 N Network gas chromatograph and a 5973Network Mass Selective Detector (5973N MSD) operating in $70 \mathrm{eV}$ electron impact ionization mode. Mass spectra were acquired in full scan mode in the range of 40-650 m/z.

The GC was equipped with a $30 \mathrm{~m}$ HP-5MS capillary column $(0.25 \mathrm{~mm}$ i.d., $0.25 \mu \mathrm{m}$ film thickness $)$ and helium was used as the carrier gas at a rate of $1 \mathrm{~mL} / \mathrm{min}$. The injector was set at $250{ }^{\circ} \mathrm{C}$ and was used in splitless mode with a splitless time of $1 \mathrm{~min}$. The oven temperature program was set at an initial temperature of $40^{\circ} \mathrm{C}$ (hold time $10 \mathrm{~min}$ ), then temperature ramp of $4{ }^{\circ} \mathrm{C} / \mathrm{min}$ up to $210^{\circ} \mathrm{C}$ and ramp of $30^{\circ} \mathrm{C} / \mathrm{min}$ to reach a final temperature of $220^{\circ} \mathrm{C}$ (final hold time $5 \mathrm{~min}$ ). The compounds were tentatively identified based on their Electron Ionization (EI) mass spectra using the NIST08 database. The identities of some detected volatile compounds were also confirmed by comparing EI mass spectra and chromatographic retention times with those of available standards. Blank experiments, including blank of the fiber and blank of the empty vial, were accomplished after each analysis in order to rule out the presence of any parasitic signals. The relative peak area percentage of each compound is achieved by the ratio between the peak area for that compound and the sum of the peak areas of all the compounds identified in the chromatogram.

\subsection{Sensory Analysis}

Muffins (M_MUF, T_MUF, and C_MUF) were evaluated by descriptive sensory analysis by a trained panel of 8 adult judges ( 5 males and 3 females, aged between 23 and 65 years, recruited among departmental faculty staff). Samples belonging to each of the three different muffin types were served in a standard sensory booth in random order unknown to the judges at room temperature, with data averaged over three replicates. Assessors were trained according to ISO 8586:2012 [39] guidelines for the selection, training and monitoring of expert sensory assessors. Additional training was given with reference products to address specific taste and appearance descriptors. Panellists cleansed with 
mineral water and non-salted crackers between samples. Training for muffin sensory attributes was given with commercially available muffins one day before actual test. Judges rated samples on a 10-point structured scale from 0 to 9 for appearance, smell, taste and texture descriptors (Table 1), with a score 0 indicating the absence of the attribute and 9 an extremely high attribute value.

Table 1. Muffin sensory descriptor list.

\begin{tabular}{ccc}
\hline Category & Descriptor & Definition \\
\hline \multirow{2}{*}{ Appearance } & Glossy & Presence of glossy crust \\
& Embrowned & Presence and intensity of crust browning \\
& Open surface & Irregularities and openings in crust surface \\
Arched & Shape of muffin top surface \\
\hline \multirow{2}{*}{ Olfactory } & Typical flavor & Product typical flavor intensity \\
& Sweet flavor & Sweetness intensity \\
\hline Typical taste & Product typical taste intensity \\
& Intensity & General taste intensity \\
& Sweet taste & Sweet taste intensity \\
& Caramel & Caramel taste intensity \\
& Bitter & Bitter taste intensity \\
& Aftertaste & General aftertaste intensity \\
\hline & Adhesiveness & Adhesion rate to mouth during test \\
& Toughness & Chewing resistance rate \\
& Dryness & Dry mouthfeel impression \\
& Bubbling & Presence of empty areas inside product \\
\hline
\end{tabular}

\subsection{Statistical Analysis}

GC-MS and antioxidant results were reported as mean \pm standard deviation (SD) (three replicates). Moreover, antioxidant data underwent one-way analysis of variance (ANOVA) using Prism GraphPad Prism version 4.0 for Windows, GraphPad Software (San Diego, CA, USA). After that, the Tukey's test was performed to compare all means. Differences between the means were statistically significant with $p<0.05$.

Regarding sensory analysis, mean results are reported in the form of spider plot graph. Descriptive data were also submitted to Principal Component Analysis (PCA). PCA analysis on sensory data was performed on all descriptor data, by using the NIPALS algorithm and with Varimax data rotation. (The Unscrambler, version 10.4, CAMO, Norway).

\section{Results and Discussion}

\subsection{Preparation and PXRD Analysis}

The solids (CT_MA and CT_TA) were prepared through the slurry process in ethanol, to obtain multifunctional solid mixtures, in which the properties of the single components remain unchanged. In particular, MA and TA were chosen for their baking activity, whereas catechin was selected for its well-known antioxidant properties [40]. Therefore, in analogy with the well-known studies of drug-excipients compatibility [41,42] physical and chemical interactions between the single components within the CT_MA and CT_TA solid mixtures are undesired since they could affect the individual properties.

The commercially available CT, according to its characteristic PXRD profile (Figure 2, black line), consists in the $\beta$-monohydrate form, which, unfortunately, displays poor water solubility [23] and therefore poor bioavailability. However, it is well known that water recrystallization of CT in its $\beta$-monohydrate polymorph can induce a phase transition into the tetrahydrate form [24]; moreover, additional catechin polymorphs, with different water solubility, have been observed, including several hydrates [25], an anhydrous form and methanol solvate form. On this basis, before preparing the 
baking powders formulation, the flavonoid $\beta$-monohydrate polymorph was slurred individually in ethanol, with the aim of investigating if a polymorphic transition occurs and, eventually, which solvate and/or hydrated form is generated. The eventual formation of the ethanol solvate would represent a great improvement in the CT bioavailability, since, according to the general rules of polymorphs solubility [26] the ethanol solvate should be more soluble than the monohydrate phase.

The resulting microcrystalline powder was analyzed through Powder X-Ray Diffraction, in order to determine the eventual CT structural modification induced by the slurry process. Indeed, the PXRD profile of $\mathrm{CT}$ after slurry in ethanol is found different from that of the $\beta$-monohydrate form, indicating the occurred solid state phase transition (Figure 2, red line).

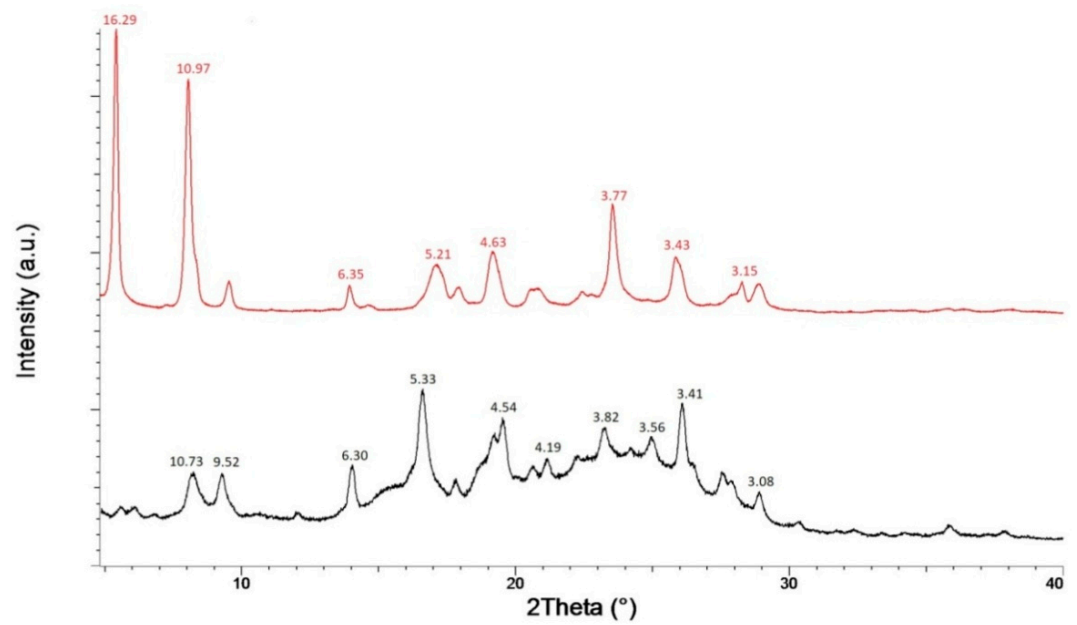

Figure 2. PXRD patterns of CT before (black line) and after (red line) slurry process. Position of the main peaks reported in $\AA$. $\mathrm{CT}=(+)$-catechin.

However, the new PXRD pattern corresponds to the tetrahydrate form of catechin [23], excluding the formation of a new ethanol solvate form. It is important to highlight that the tetrahydrate form of catechin displays higher water solubility than the $\beta$-monohydrate. Since, to the best of our knowledge, water solubility quantitative measurements of the catechin tetrahydrate form have never been reported, the water solubility of the obtained resulting powder was measured and compared with that of the $\beta$-monohydrate form; in particular the solubility values in water are $4.6 \mathrm{mg} \mathrm{mL}^{-1}$ for catechin $\beta$-monohydrate and $8.0 \mathrm{mg} \mathrm{mL}^{-1}$ for catechin tetrahydrate. Moreover, although generally a soluble polymorph is less stable than the insoluble one, converting to the thermodynamically more stable and less soluble form [27] in this case, the catechin tetrahydrate polymorph is very stable, as demonstrated by the absence of any change in its PXRD pattern recorded over time (Figure 3).

In order to verify the absence and/or presence of intermolecular interactions between the flavonoid CT and the two organic acids (MA and TA), the PXRD profiles of the solid mixtures, CT_MA and CT_TA, were acquired and compared to those of their relative components (Figures 2 and 3). As expected, the slurry process induces the flavonoid solid phase conversion, thus, the PXRD patterns of the sample CT_MA and CT_TA may be regarded as the overlap of CT tetrahydrate and MA and TA diffractograms (Figures 4 and 5, respectively). The formation of CT tetrahydrate during the slurry process determines an increase of the water-solubility of CT_MA and CT_TA with respect to monohydrate form of the flavonoid; in particular, the solubility values in water are 6.0 and $40.0 \mathrm{mg} \mathrm{mL}^{-1}$ for CT_MA and CT_TA, respectively. 


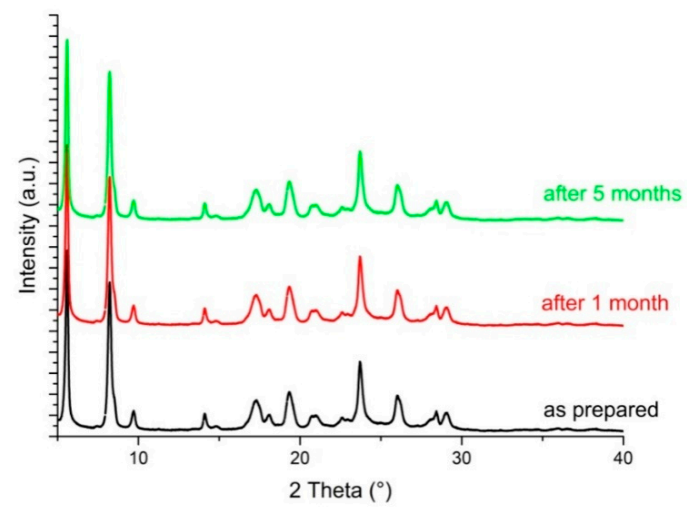

Figure 3. PXRD pattern of (+)-catechin tetrahydrate recorded as prepared (black line), after 1 month (red line) and after 5 months (green line).

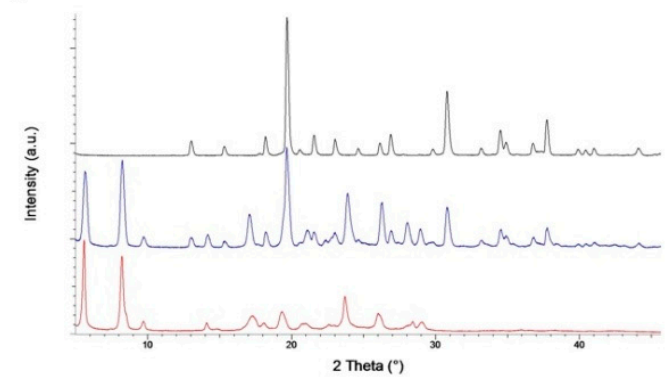

b

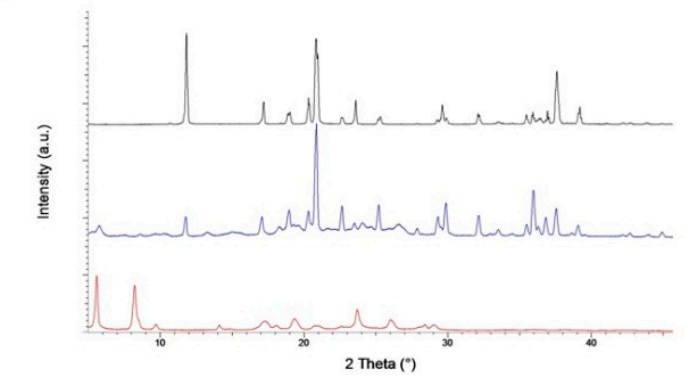

Figure 4. PXRD patterns of: (a) CT tetrahydrate (red line), the solid mixture CT_MA (blue line) and MA (black line); (b) CT tetrahydrate (red line), the solid mixture CT_TA (blue line) and TA (black line). $\mathrm{CT}=(+)$-Catechin; $\mathrm{CT} \_\mathrm{MA}=(+)$-catechin_mucic acid adduct; MA = Mucic acid. CT_TA $=(+)$-catechin_tartaric acid adduct; $\mathrm{TA}=$ Tartaric acid.

Thus, the presence of the distinctive diffraction peaks of the individual component in both samples (CT_MA and TA_CT) diffractograms, and the absence of new reflections allow us to exclude the formation of any intermolecular interactions, with eventual formation of new supramolecular species, between the flavonoid and the two organic acids. Hence, since the individual components remain unchanged after the treatment, it is reasonable to assume that they may retain their individual properties within the solid state mixtures.

\subsection{Antioxidant Performances of Baking Additives}

Antioxidant properties of the phenolic compounds makes these molecules very interesting due to their ability to prevent different human diseases related to the oxidative stress [43]. Moreover, in recent years the consumers' attention was particularly focused to the knowledge of the antioxidant performances of the consumed foods [44]. To this regard, the baking agents prepared by CT_MA and CT_TA can be a useful tool to make bakery products with remarkable antioxidant properties. Total phenolic content and antioxidant properties of $\mathrm{M} \_\mathrm{BP}$ and T_BP were investigated and the results reported in Table 2. Additionally, C_BP was employed as control. 
Table 2. Antioxidant performances of baking powders. Data are presented asmean $\pm \mathrm{SD}(n=3)$, different letters in the same columns are statistically different $(p<0.05)$.

\begin{tabular}{|c|c|c|c|c|}
\hline \multirow{2}{*}{ Baking } & \multirow{2}{*}{$\begin{array}{c}\text { TPC } \\
\text { (meq CT/g Baking) }\end{array}$} & \multirow{2}{*}{$\begin{array}{c}\text { TAC } \\
\text { (meq CT/g Baking) }\end{array}$} & \multicolumn{2}{|c|}{$\mathrm{IC}_{50}\left(\mathrm{mg} \mathrm{mL}^{-1}\right)$} \\
\hline & & & DPPH Radical & ABTS Radical \\
\hline T_BP & $0.0298 \pm 0.021^{b}$ & $0.0081 \pm 0.0009^{b}$ & $2.358 \pm 0.076^{\mathrm{a}}$ & $0.149 \pm 0.011^{a}$ \\
\hline M_BP & $0.0530 \pm 0.035^{a}$ & $0.0119 \pm 0.0011^{\mathrm{a}}$ & $0.518 \pm 0.015^{b}$ & $0.112 \pm 0.010^{b}$ \\
\hline C_BP & - & - & - & - \\
\hline $\begin{array}{c}\text { Positive } \\
\text { control } \\
\text { Ascorbic acid }\end{array}$ & & $0.1086 \pm 0.0124$ & $4.785 \pm 0.126$ & $1.654 \pm 0.099$ \\
\hline
\end{tabular}

The results display the baking powders showing interesting antioxidant properties as a consequence of the introduction of molecules having polyphenol structure. On the contrary, C_BP do not show any activity. Specifically, all the assays underlined as antioxidant performances of M_BP were statistically better than T_BP $(p<0.05)$. This trend was particularly evident by observing the $\mathrm{IC}_{50}$ value related to the scavenger activity in the organic environment, against DPPH radical, with a value almost five times lower for M_BP with respect to T_BP.

\subsection{Rheological Characterization}

Dynamic rheological tests (frequency sweep experiments), at 15 and $25{ }^{\circ} \mathrm{C}$, respectively, were carried out to study the dough samples. Macroscopically, one usually observes a liquid structure for the samples. Strain-sweep experiments that are not reported here revealed that all samples have a nonlinear response at a considerably higher strain. The dynamic moduli for all samples lose linearity at ca. $100 \%$ strain at a frequency of $1 \mathrm{~Hz}$.

The mechanical spectrum reflects the texture structure of the system. In Figure 5, the rheological spectra were reported for all samples. It is worthy to note differences in $G^{*}$ (Figure 5 ) where all values are higher than those of muffin dough without baking (WY). It is also important to note that MUC and TAR samples show similar rheological behaviour. Their frequency profiles are higher than those of other ones. These results indicate that the synthesized baking affects the structures of the system and improve the mechanical properties of the doughs.

The variation of viscosity versus time at different shear rates for samples was measured (Figure 5). It was observed that different samples have different rheological behaviors. A thinning behavior is shown, where the viscosity is dependent on shear rates. Higher shear rates reduce the viscosity such as in a shear-thinning fluid, also known as a pseudo plastic system. The shear thinning behavior appears increasingly pronounced when tartaric is used. The pseudo plastic fluid and higher viscosity can be attributed to higher structure-forming interactions $[45,46]$. 

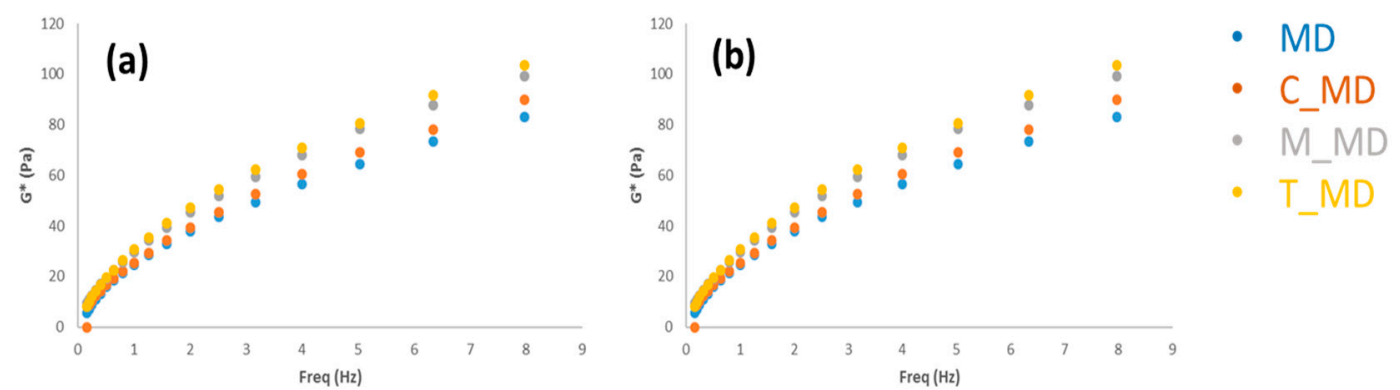

Figure 5. Frequency Sweep Test muffin dough $\left(\mathrm{G}^{*}\right) .(\mathbf{a}): 15^{\circ} \mathrm{C},(\mathbf{b}): 25^{\circ} \mathrm{C} . \mathrm{MD}=$ muffin dough without baking; T_MD = muffin dough with T_BP; $\mathrm{M} \_M D=$ muffin dough with $\mathrm{M} \_B P ; C \_M D=$ muffin dough with C_BP.

In Figure 6, the frequency sweep tests of baked muffins achieved employing the synthetic baking (M_MUF and T_MUF) and commercial one (C_MUF) are reported. It is worthy to note the effects of different baking on the rheological properties of the final products. The trends are almost flat in frequency (the structure is formed by large network thus a high coordination number); additionally, the higher values as a function of the frequency observed for T_MUF and M_MUF can be related to the higher "interaction strength" between the rheological units (stronger links).

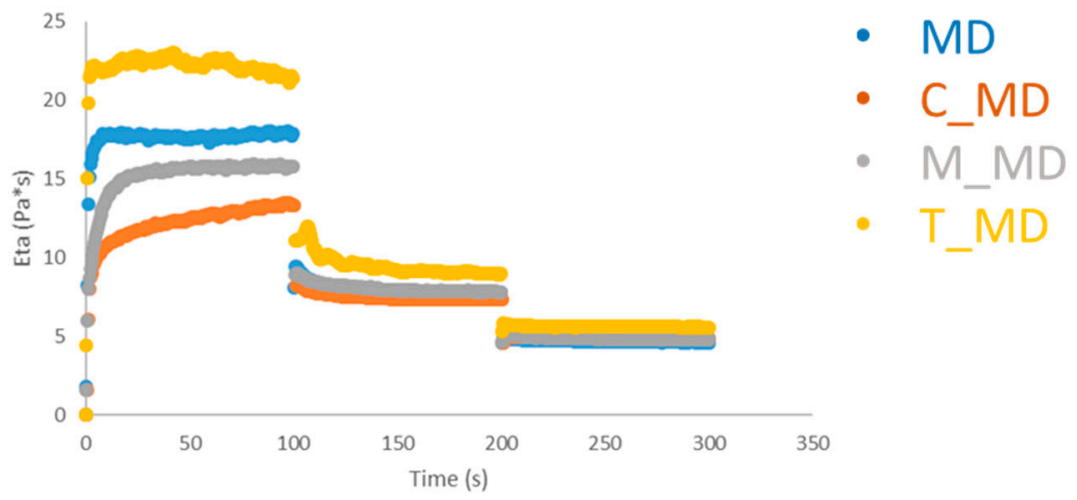

Figure 6. Step Rate muffin dough at $15^{\circ} \mathrm{C}$. $\mathrm{MD}=$ muffin dough without baking; $\mathrm{T} \_\mathrm{MD}=$ muffin dough with T_BP; M_MD = muffin dough with $\mathrm{M} \_B P ; C \_M D=$ muffin dough with C_BP.

This means that the synthetic baking ingredients (M_MUF and T_MUF) form more structured samples [47].

Similar trends are observable between them, while they are different in comparison with the C_MUF sample (Figure 7).

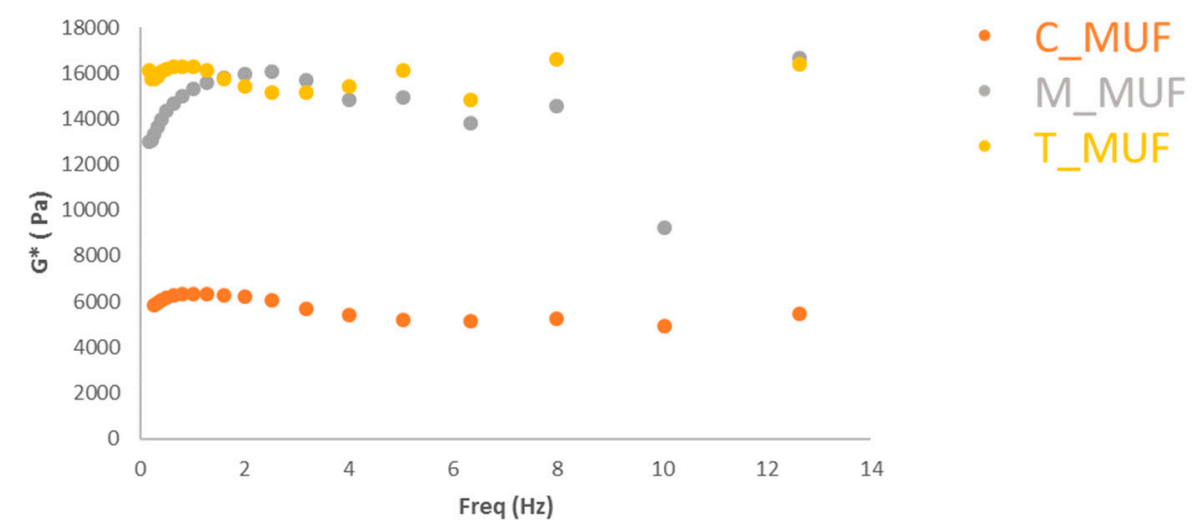

Figure 7. Frequency Sweep Test at $25^{\circ} \mathrm{C}$ muffin. C_MUF = Muffin prepared by C_BP; M_MUF = Muffin prepared by M_BP; T_MUF = Muffin prepared by T_BP. 


\subsection{Antioxidant Performances of Muffins}

The use of antioxidant baking powders could represent an innovative tool to achieve antioxidant food products [7]. To this regard, muffins underwent an extraction procedure in order to attain extracts rich in polyphenols [38]. The extracts were investigated to determine the antioxidant performances of the final product and the results are reported in Table 3.

The data clearly showed that the employment of functional baking ingredients led to a product with antioxidant properties, with respect to the control C_MUF that did not display any activity. Specifically, the analysis of TPC allows us to note that the highest value was recorded for T_MUF (0.00175 meq CT/g muffin), while the best performing compound was M_BP. This different trend certainly underlines the role organic acid in the prevention of the antioxidant feature loss during the preparation of the muffins, i.e., catechin oxidation, isomerization, and degradation. In particular, the catechinisomerization could easily take place under the stated processing conditions, strongly depending on temperature and $\mathrm{pH}$ [48]. Higher values of $\mathrm{pH}$ and temperature decrease the stability of the catechin [49].

Table 3. Antioxidant properties of the prepared muffins. Data are presented as mean $\pm \operatorname{SD}(n=3)$, different letters in the same columns are statistically different $(p<0.05)$.

\begin{tabular}{|c|c|c|c|c|}
\hline \multirow{2}{*}{ Muffin } & \multirow{2}{*}{$\begin{array}{c}\text { TPC } \\
\text { (MeqCT/g Muffin) }\end{array}$} & \multirow{2}{*}{$\begin{array}{c}\text { TAC } \\
\text { (MeqCT/g Muffin) }\end{array}$} & \multicolumn{2}{|c|}{$\mathrm{IC}_{50}\left(\mathrm{mg} \mathrm{mL}^{-1}\right)$} \\
\hline & & & DPPH Radical & ABTS Radical \\
\hline T_MUF & $0.00175 \pm 0.00012^{a}$ & $0.00107 \pm 0.00007^{\mathrm{a}}$ & $1.236 \pm 0.027^{b}$ & $0.098 \pm 0.004^{b}$ \\
\hline M_MUF & $0.00120 \pm 0.00010^{b}$ & $0.00062 \pm 0.00003^{b}$ & $2.251 \pm 0.035^{\mathrm{a}}$ & $0.789 \pm 0.013^{a}$ \\
\hline C_MUF & - & - & - & - \\
\hline $\begin{array}{c}\text { Positive control } \\
\text { Ascorbic acid }\end{array}$ & & $0.1086 \pm 0.0124$ & $4.785 \pm 0.126$ & $1.654 \pm 0.099$ \\
\hline
\end{tabular}

TPC = Total Phenolic Content; TAC $=$ Total Antioxidant Capacity CT $=$ Catechin; DPPH $=2,2^{\prime}$-difenyl-1- picrylidrazil; ABTS $=2,2^{\prime}$-azino-bis(3-etylbenzotiazolin-6-sulphonic).C_MUF = Muffin prepared by C_BP; M_MUF = Muffin prepared by M_BP; T_MUF = Muffin prepared by T_BP. (-) = not detected.

The data regarding TPC values was confirmed in the analyses of the antioxidant performances of the products. TAC and scavenger activities, both in organic and aqueous environments, highlighted T_MUF as the best performing product concerning the antioxidant properties. In detail, TAC and scavenger activity against DPPH radical was almost two times improved in T_MUF, while in an aqueous environment against ABTS radical, the $\mathrm{IC}_{50}$ value recorded for M_MUF appears almost one order of magnitude higher than T_MUF.

A comparison of the recorded data with other enriched muffins is very difficult because usually active molecules were added to the dough. On the contrary, our approach is quite different and allowed us to impart antioxidant features to the final product by using a baking agent with antioxidant peculiarities. Recently, muffins enriched with different amounts of a by-product of chia oil extraction $(2.5-10 \% w / w)$ or pomegranate peel supplementation $(5-10 \% w / w)$ showing antioxidant features that displayed TPC value and antioxidant performances in the same order of magnitude of the products proposed in this research [50,51].

\subsection{Analysis of Volatile Compounds in Muffins}

The approach used for the determination of the volatile fraction in muffins is based on the headspace analysis by solid-phase microextraction (HS-SPME) technique [52,53] combined with gas chromatography/mass spectrometry (GC/MS), analytical technique chosen in order to separate and identify the different extracted volatile compounds [54,55].

The volatile compounds of muffin samples (M_MUF, T_MUF, and C_MUF), were extracted from the solid matrix by DVB/CAR/PDMS fiber and then analyzed by GC/MS.

In Figure 8 are reported the GC profiles obtained analysing the muffin samples (M_MUF, T_MUF, C_MUF). 
In the GC profiles (Figure 8) of the analyzed samples, about 29 volatile compounds, belonging to different chemical classes, were tentatively identified by matching the corresponding mass spectra to those of the mass spectral library or by comparing retention times and mass spectra with those of available standards (Table 4). The relative peak area percentage for each compound was defined as the ratio between the peak area for that compound and the sum of all identified peaks areas in that sample.
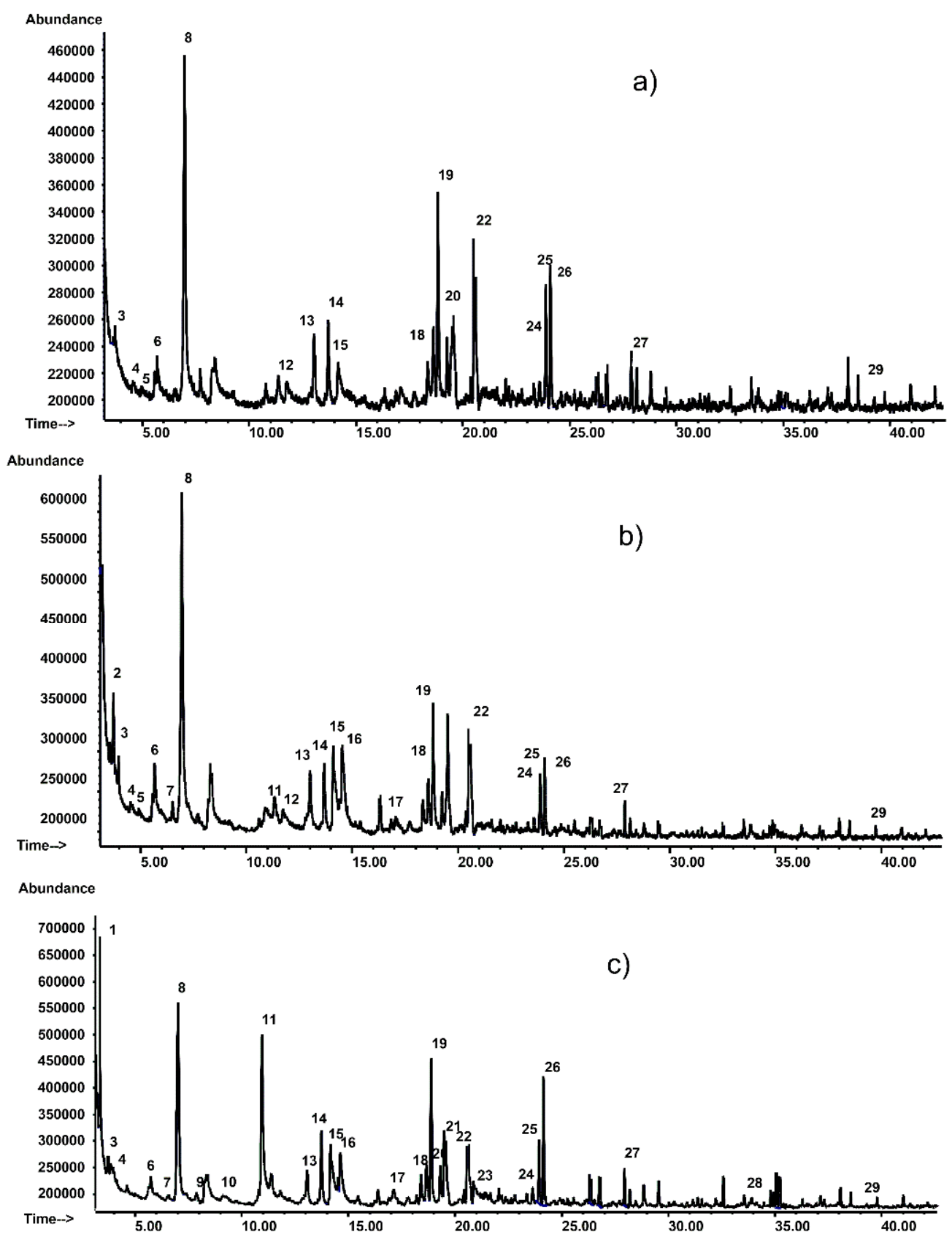

Figure 8. HS-SPME/GC-MS (EI) analysis of: (a) muffin sample M_MUF; (b)muffin sample T_MUF; (c) muffin sample C_MUF. M_MUF = Muffin prepared by M_BP; T_MUF = Muffin prepared by T_BP; C_MUF $=$ Muffin prepared by C_BP. Numbers 1-29 indicate the identified compounds reported in Table 4. 
Table 4. Identified volatile compounds and their retention times in three different muffin formulations. Data represent mean $\pm \mathrm{SD}(n=3)$.

\begin{tabular}{|c|c|c|c|c|c|c|}
\hline No & Analyte & $\begin{array}{l}\text { Method of } \\
\text { Identification }\end{array}$ & $t_{R}(\min )$ & M_MUF \% * & T_MUF \% * & C_MUF \% * \\
\hline 1 & 1-hydroxy-2-propanone & $\alpha$ & 3.25 & - & - & $15.29 \pm 1.06$ \\
\hline 2 & 2-Methylbutanal & $\alpha, \beta$ & 3.56 & - & $1.39 \pm 0.25$ & - \\
\hline 3 & 3-Methylbutanal & $\alpha, \beta$ & 3.72 & $2.39 \pm 0.13$ & $2.89 \pm 0.08$ & $1.92 \pm 0.16$ \\
\hline 4 & Pyrazine & $\alpha$ & 4.56 & $0.62 \pm 0.09$ & $0.82 \pm 0.12$ & $0.43 \pm 0.1$ \\
\hline 5 & Pyridine & $\alpha, \beta$ & 4.91 & $0.43 \pm 0.06$ & $0.18 \pm 0.05$ & - \\
\hline 6 & Toluene & $\alpha, \beta$ & 5.6 & $1.53 \pm 0.16$ & $1.71 \pm 0.11$ & $0.88 \pm 0.09$ \\
\hline 7 & 1-Pentanol & $\alpha$ & 5.69 & - & $5.18 \pm 0.15$ & $1.41 \pm 0.13$ \\
\hline 8 & Hexanal & $\alpha, \beta$ & 6.98 & $28.29 \pm 0.55$ & $29.67 \pm 0.08$ & $17.37 \pm 0.56$ \\
\hline 9 & Methylpyrazine & $\alpha$ & 8.2 & - & - & $0.78 \pm 0.15$ \\
\hline 10 & 2-Furancarboxaldehyde & $\alpha, \beta$ & 9.07 & - & - & $0.32 \pm 0.12$ \\
\hline 11 & 2-Furanmethanol & $\alpha, \beta$ & 10.87 & - & $0.58 \pm 0.26$ & $13.66 \pm 0.73$ \\
\hline 12 & 1,3-dimethylbenzene & $\alpha, \beta$ & 11.34 & $3.45 \pm 0.59$ & $2.47 \pm 0.31$ & - \\
\hline 13 & 2-Heptanone & $\alpha$ & 13.04 & $4.79 \pm 0.58$ & $5.75 \pm 0.25$ & $2.84 \pm 0.28$ \\
\hline 14 & Heptanal & $\alpha, \beta$ & 13.7 & $5.64 \pm 0.25$ & $4.21 \pm 0.16$ & $4.75 \pm 0.22$ \\
\hline 15 & 2,5-dimethylpyrazine & $\alpha$ & 14.15 & $13.17 \pm 0.65$ & $10.58 \pm 0.17$ & $4.22 \pm 0.44$ \\
\hline 16 & 2(5H)-Furanone & $\alpha$ & 14.58 & - & $5.33 \pm 0.43$ & $4.76 \pm 0.1$ \\
\hline 17 & Benzaldehyde & $\alpha, \beta$ & 17.08 & - & $1.82 \pm 0.41$ & $0.52 \pm 0.12$ \\
\hline 18 & 1-octen-3-ol & $\alpha, \beta$ & 18.36 & $3.54 \pm 0.06$ & $2.61 \pm 0.07$ & $1.91 \pm 0.17$ \\
\hline 19 & 2-pentylfuran & $\alpha$ & 18.84 & $10.69 \pm 0.48$ & $8.72 \pm 0.15$ & $8.35 \pm 0.29$ \\
\hline 20 & Decane & $\alpha$ & 19.26 & $3.24 \pm 0.46$ & $2.71 \pm 0.12$ & $2.22 \pm 0.14$ \\
\hline 21 & Octanal & $\alpha, \beta$ & 19.45 & - & - & $3.61 \pm 0.15$ \\
\hline 22 & Benzene,1-methyl-4-(1-ethylethyl) & $\alpha$ & 20.38 & $1.4 \pm 0.14$ & $1.22 \pm 0.11$ & $0.75 \pm 0.11$ \\
\hline 23 & 2-Ethyl-1-hexanol & $\alpha$ & 20.86 & - & - & $0.71 \pm 0.21$ \\
\hline 24 & 2-Nonanone & $\alpha$ & 23.59 & $1.81 \pm 0.04$ & $1.29 \pm 0.06$ & $1.09 \pm 0.05$ \\
\hline 25 & Undecane & $\alpha$ & 23.88 & $5.98 \pm 0.24$ & $3.34 \pm 0.13$ & $3.15 \pm 0.28$ \\
\hline 26 & Nonanal & $\alpha, \beta$ & 24.1 & $7.69 \pm 0.14$ & $4.21 \pm 0.08$ & $5.88 \pm 0.16$ \\
\hline 27 & Dodecane & $\alpha$ & 27.89 & $3.16 \pm 0.25$ & $1.87 \pm 0.11$ & $1.58 \pm 0.06$ \\
\hline 28 & Tetradecane & $\alpha$ & 34.87 & - & - & $0.65 \pm 0.03$ \\
\hline 29 & 2,5-dibutylthiophene & $\alpha$ & 39.74 & $1.9 \pm 0.15$ & $0.77 \pm 0.02$ & $0.40 \pm 0.06$ \\
\hline
\end{tabular}

* relative peak area percentage. ${ }^{\alpha}$ Identification by NIST08 library. ${ }^{\beta}$ Identification based on standard samples;

C_MUF = Muffin prepared by C_BP; M_MUF = Muffin prepared by M_BP; T_MUF = Muffin prepared by T_BP. (-)

$=$ not detected.

The obtained aromatic profiles are due to several factors, mainly related to the lipid oxidation and thermal degradation of sugars and free amino acids through caramelization and Maillard reactions during cooking. They are characterized by the presence of aldehydes, hydrocarbons, ketones, alcohols, furans, pyrazines, and sulphur-containing compounds.

Concerning aldehydes, the presence of 3-methylbutanal, 2-methylbutanal, hexanal, nonanal, heptanal, 2-furancarboxaldehyde, octanal, and benzaldehyde was observed (Table 4). 3-methylbutanal $\left(t_{R}=3.72\right.$ min., analyte 3, Table 4), detected in all muffin samples and responsible of malty odour, is an aldehyde deriving from oxidative deamination and decarboxylation of leucine in the presence of carbonyl compounds (Strecker degradation), while 2-methylbutanal (Sample T_MUF) is originated from isoleucine. In Table 4, it can be observed that hexanal, a typical compound of linoleic and arachidonic acids oxidation, is the major aldehyde component in all analyzed muffin samples, followed by nonanal, heptanal, and octanal, the latter of which is detected only in C_MUF, which are formed by oxidation of oleic acid [56].

Benzaldehyde, detected in samples T_MUF and C_MUF, which can be considered a Strecker aldehyde, originated from the reaction of the parent $\alpha$-amino acid (phenylglycine) with $\alpha$-dicarbonyl compounds from lipid decomposition [56].

In the group of ketones-in addition to identifying in all muffin samples 2-heptanone and 2-nonanone mainly originating from lipid oxidation-was detected, exclusively in C_MUF muffin, the compound 1-hydroxy-2-propanone formed through the Strecker degradation of proline. This molecule is a precursor of $\alpha$-aminoketones that on auto-condensation and subsequent oxidation and condensation with fatty aldehydes and ketones generate pyrazine derivatives [57]. Alkylpyrazines can be also originated from the Maillard reactions of free amino acids and reducing sugars. 
Pyrazine $\left(t_{R}=4.56\right.$ min., analyte 4 , Table 4$)$ and 2,5-dimethylpyrazine $\left(t_{R}=14.15\right.$ min., analyte 15 , Table 1), were observed in all three muffin types (Table 4).

In the group of heterocyclic compounds, besides identification of pyrazine compounds, pyridine $\left(t_{R}=4.91\right.$ min., analyte 5, Table 4$)$ and 2,5-dibutylthiophene $\left(t_{R}=39.74 \mathrm{~min}\right.$. , analyte 29 , Table 4$)$ were detected. Heterocyclic compounds containing sulphur and nitrogen atoms are mainly formed through the interaction of Maillard reaction intermediates with lipid decomposition products such as 2,4-decadienal and hexanal.

Substituted-furans such as 2-furancarboxaldehyde, 2-furanmethanol, 2(5H)-furanone and 2-pentylfuran were also detected (Table 4). These compounds are formed through the complex processes of Maillard reaction and sugar thermal degradation during baking [58]. 2-pentylfuran is the only furan derivative detected in all muffin samples $\left(t_{R}=18.84 \mathrm{~min}\right.$., analyte 19 , Table 4$)$. The formation of 2-pentylfuran could be attributed both to Maillard reaction and lipid oxidation [59].

Hydrocarbon compounds like toluene, 1,3-dimethylbenzene, decane, undecane and dodecane detected in all muffin samples (Table 4), could come from the oxidative decomposition of lipids and are often associated with grassy and fatty flavors [60].

Among the volatile components that contribute to the aroma of all analyzed muffin samples we also found 1-octen-3-ol $\left(t_{R}=18.36\right.$, analyte 18 , Table 4$)$, a compound with a strong mushroom note that is associated with the enzymatic degradation of linoleic acid [61]. Other detected alcohols are 1-pentanol (sample T_MUF and C_MUF) and 2-ethyl-1-hexanol (sample C_MUF).

Some volatile molecules like 1-hydroxy-2-propanone, methyl pyrazine, 2-furancarboxaldehyde, 2-ethyl-1-hexanol, octanal, and tetradecane (Table 4) were detected exclusively in the extract of C_MUF.

In the GC profile of the control (C_MUF) is observed the presence of a higher number of volatile components compared to T_MUF and M_MUF muffins.

The obtained results show that volatile compounds that derive from lipid oxidation and thermal degradation of sugars and free amino acids affect the flavor of these products.

\subsection{Muffin Sensory Analysis}

Sensory profiles for C_MUF, T_MUF and M_MUF muffins are shown on Figure 9.

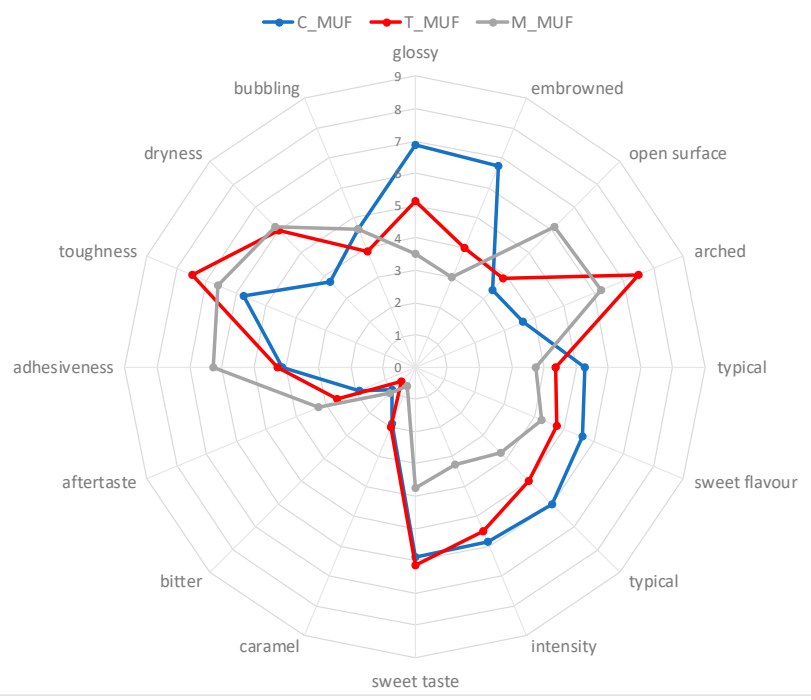

Figure 9. Sensory profile of C_MUF, M_MUF and T_MUF muffin samples. C_MUF = Muffin prepared by C_BP; M_MUF = Muffin prepared by M_BP; T_MUF = Muffin prepared by T_BP. 0-9 = Judge scores from 10-point structured scale. 
The main appearance descriptors were found to be the presence of a glossy crust, irregularities and openness in crust surface rate, and an arched shape of the muffin top surface. The main olfactory descriptor was muffin sweet flavor, while the principal taste descriptors were typical muffin taste, general taste, and sweet taste intensity; textural descriptors adhesiveness, toughness, mouthfeel dryness, and bubbling were all actively recognized by panelists. T_MUF and M_MUF muffins differentiated from control (C_MUF) for lower glossy crust and browning, while showing higher values of open surface and arched top surface. Flavor descriptors did not show significant differences, and taste profile showed generally lower values for T_MUF and M_MUF muffins as compared to the control. Textural descriptors were higher for modified muffins from control.

PCA (Principal Component Analysis) was performed on sensory data in order to explore variability between descriptors. Analysis was performed on all descriptors observed, with the first principal component explaining $27 \%$ of total variation and second component expressing $21 \%$ of total variation. PCA score results (Figure 10) show a good representation of muffin groups, with T_MUF and M_MUF types partially overlapping but quite clearly separated from control muffin group, that concentrates almost completely in the positive quadrant of both principal components. Such group is correlated (Figure 11) with presence of glossy and embrowned crust, sweet taste and flavor, typical taste and flavor, and general taste intensity. T_MUF muffins appear to be correlated to caramel taste intensity, sweet flavor, and bitter taste intensity. M_MUF muffins, on the contrary, appear more correlated the arched top surface descriptor, along with structural toughness and dryness and irregularities and openings in crust surface.

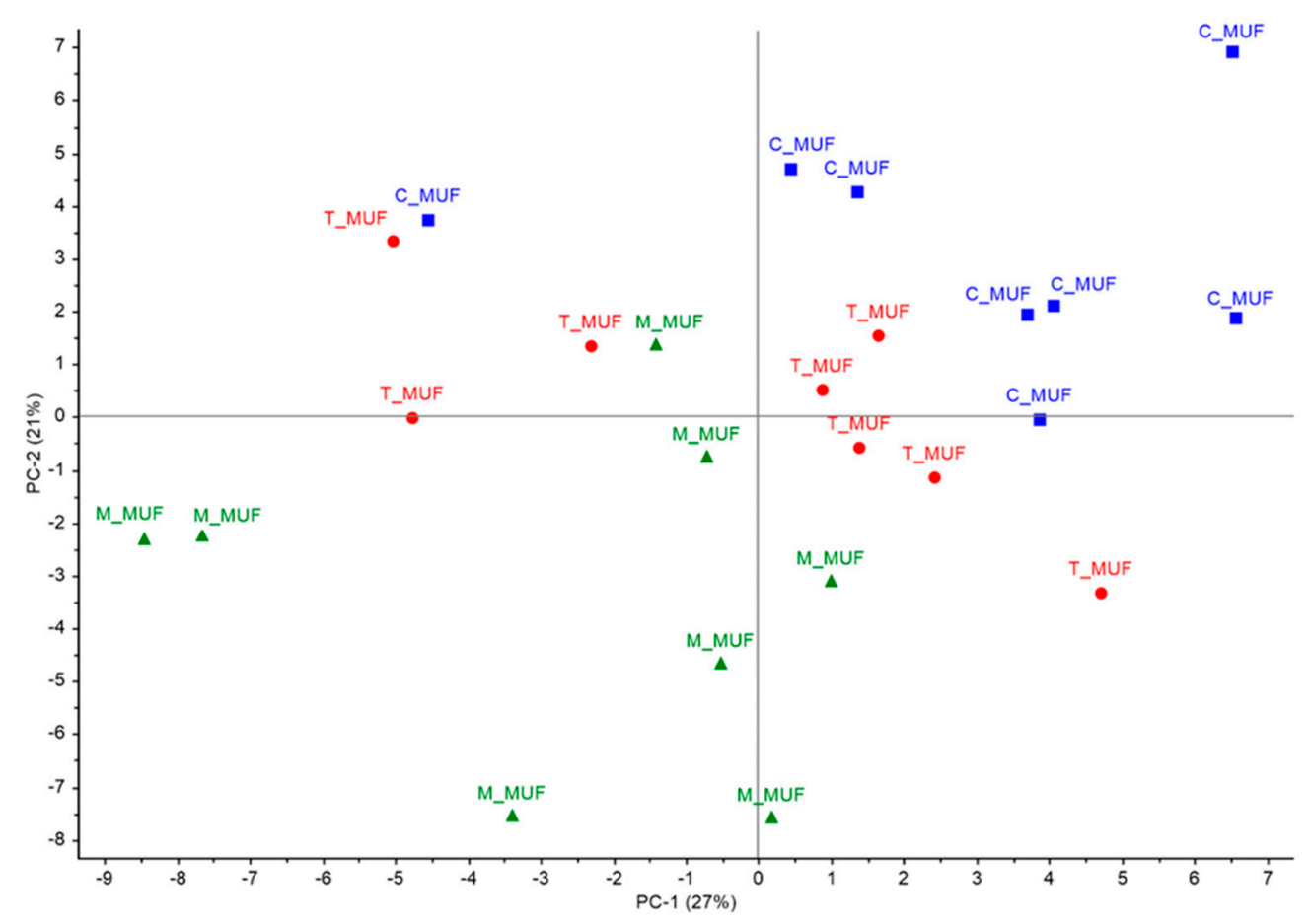

Figure 10. PCA Score plot of sensory evaluation of C_MUF, M_MUF and T_MUF muffin samples. C_MUF = Muffin prepared by C_BP; M_MUF = Muffin prepared by M_BP; T_MUF = Muffin prepared by T_BP. 


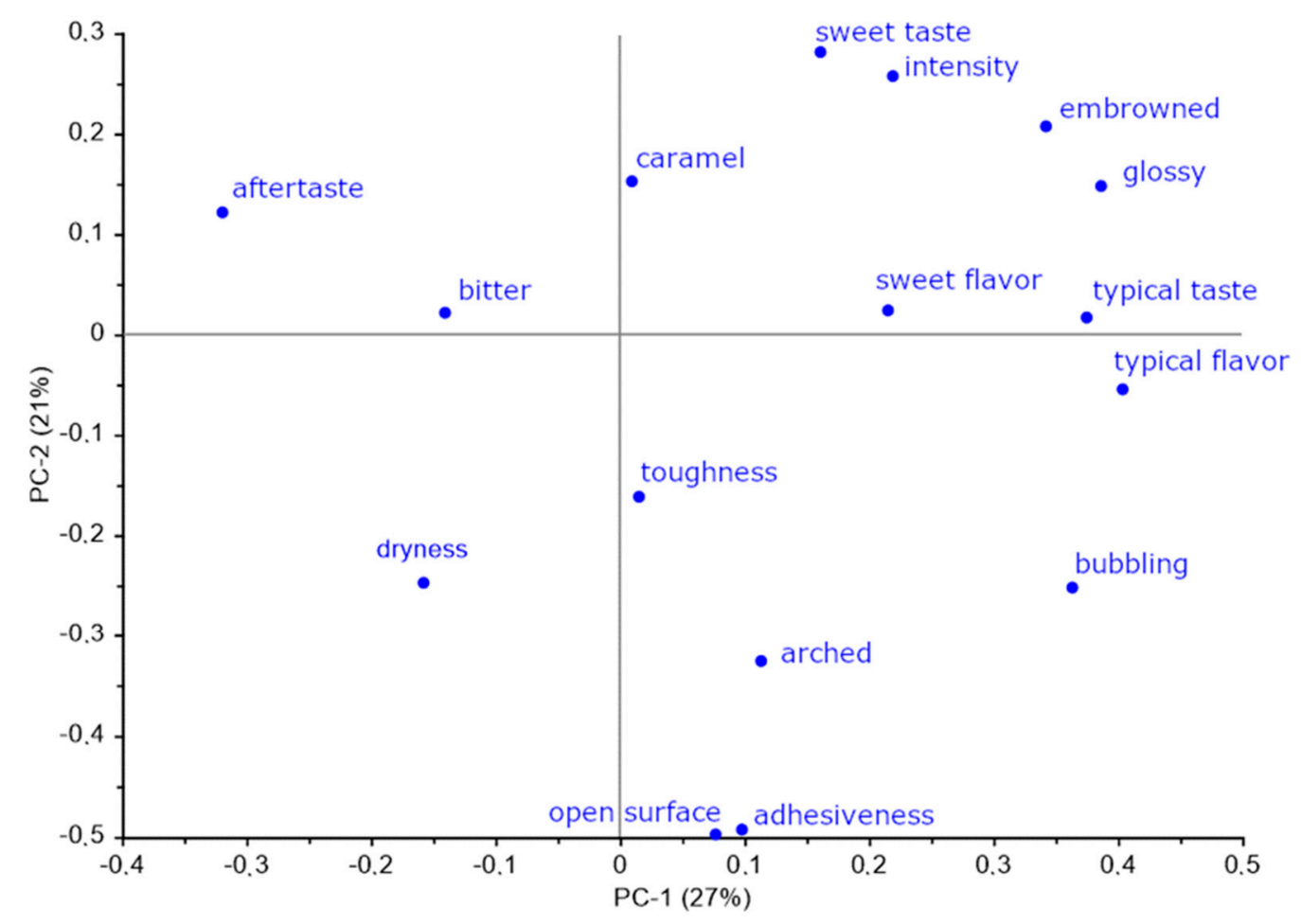

Figure 11. PCA loading plot of sensory attributes of muffin samples.

\section{Conclusions}

Multi-functional solid mixtures with antioxidant properties were synthesized, characterized, and proposed as innovative leavening agents for muffin production. The PXRD analysis demonstrated the formation of two multifunctional solid mixtures, CT_MA and CT_TA, consisting of a soluble polymorph of (+)-catechin (catechin tetrahydrate) and two organic acids (mucic and tartaric acid, respectively). The XRD pattern evaluation allowed us to suppose the maintenance of the individual properties of both components (i.e., baking and antioxidant activity). These aspects were confirmed by evaluating the antioxidant and rheological features of the leavening formulations. The commercial baking agent and its derived muffin samples showed negligible antioxidant properties and lower mechanical features in comparison to their innovative counterparts. In this sense, the replacement of phosphate additives with the new baking powder could improve the quality of the product either under the technological or under the nutritional point of view.

On the contrary, GC-MS, as well as taste analyses, revealed for modified muffins fewer volatile compounds and worse sensory traits, in comparison to the control; flavor descriptors did not show significant differences while textural descriptors were higher. Inferior taste characteristics surely represent a drawback, implying a lower consumer acceptance; however, it should be underlined that commercial formulations always include flavoring agents, (i.e., vanillin), while the CT_MA- and the CT_TA-based powders did not consider any flavor additive. It follows that with a more comprehensive formulation of the proposed leavening powders, the improvement of the taste features should be easily attainable.

Keeping in mind that, excluding infants, baked products are the main food categories contributing to the total P dietary exposure, the replacement of phosphate additives with a new baking ingredient could limit the overall intake. In this sense, it should be considered that the indication of the phosphorus concentration is not mandatory on the food labels as well as the use of other ingredients containing phosphorus. Only the presence of additives must be labelled, but not their quantities. 
Moreover, the improved antioxidant and mechanical features of such innovative agents represent important advantages and the possibility to obtain the singular components from agro-food wastes, makes their exploitation even more attractive.

Further studies should be necessary to evaluate carefully all the ingredients included in the formulation, in order to correct specific sensory defects.

Author Contributions: Conceptualization, G.C., D.R. and F.A.; methodology, G.C., C.O.R., A.M., A.L., A.C., U.G.S.; software, F.S., C.O.R., E.L.B., A.M.; validation, G.C., U.G.S., P.C.; formal analysis, G.C., F.S., E.L.B., P.C., A.M., U.G.S.; investigation, G.C., F.S., E.L.B., P.C., A.M., U.G.S.; resources, C.O.R., A.L., A.C., D.R., F.A.; data curation, G.C., F.S., E.L.B., P.C., A.M., U.G.S.; writing-original draft preparation, F.S., P.C., A.M., A.L., U.G.S.; writing-review and editing, G.C., U.G.S., D.R., F.A.; visualization, F.S., P.C., A.M., A.L., U.G.S.; supervision, C.O.R., A.L., A.C., D.R., F.A.; project administration, D.R., F.A.; funding acquisition, C.O.R., A.L., A.M., A.C., D.R., F.A. All authors have read and agreed to the published version of the manuscript.

Funding: This research received no external funding.

Acknowledgments: The authors are grateful to Francesca Mazzei (Biafora Resort \& Spa, Località Torre Garga, S.S. 107, 87055 San Giovanni in Fiore, Cosenza, Italy) and MelaniaCarullo (Bar PasticceriaColosseo, Via Alcide De Gasperi 1a, 87054 Rogliano, Cosenza, Italy), the pastry chefs that helped us in formulating the final baking powders and also for the preparation of the muffins.

Conflicts of Interest: The authors declare no conflict of interest.

\section{References}

1. Rosales-Soto, M.U.; Powers, J.R.; Alldredge, J.R. Effect of mixing time, freeze-drying and baking on phenolics, anthocyanins and antioxidant capacity of raspberry juice during processing of muffins. J. Sci. Food Agric. 2012, 92, 1511-1518. [CrossRef]

2. Ureta, M.M.; Olivera, D.F.; Salvadori, V.O. Quality Attributes of Muffins: Effect of Baking Operative Conditions. Food Bioprocess Technol. 2014, 7, 463-470. [CrossRef]

3. Diez-Sánchez, E.; Llorca, E.; Tárrega, A.; Fiszman, S.; Hernando, I. Changing chemical leavening to improve the structural, textural and sensory properties of functional cakes with blackcurrant pomace. LWT 2020, 127, 109378. [CrossRef]

4. Johnson, J.; Schuette, J. Food Science, Technology and Nutrition, Reducing Salt in Foods (Second Edition); Beeren, C., Groves, K., Titoria, P.M., Red, Eds.; Woodhead Publishing Series; Woodhead Publishing: Sawston, Cambridge, UK, 2019; pp. 231-253. ISBN 9780081008904.

5. Younes, M.; Aquilina, G.; Castle, L.; Engel, K.H.; Fowler, P.; Frutos Fernandez, M.J.; Fürst, P.; Gürtler, R.; Husøy, T.; Mennes, W.; et al. Re-evaluation of phosphoric acid-phosphates-di-, tri- and polyphosphates (E 338-341, E 343, E 450-452) as food additives and the safety of proposed extension of use. EFSA J. 2019, 17. [CrossRef]

6. Visioli, F.; de la Lastra, C.A.; Andres-Lacueva, C.; Aviram, M.; Calhau, C.; Cassano, A.; D'Archivio, M.; Faria, A.; Favé, G.; Fogliano, V.; et al. Polyphenols and human health: A prospectus. Crit. Rev. Food Sci. Nutr. 2011, 51, 524-546. [CrossRef]

7. Nagarajaiah, S.B.; Ramakrishna, M.G.; Prakash, J. Nutritional, antioxidant and sensory properties of value added muffins. Curr. Nutr. Food Sci. 2019, 15, 454-466. [CrossRef]

8. Carullo, G.; Spizzirri, U.G.; Loizzo, M.R.; Leporini, M.; Sicari, V.; Aiello, F.; Restuccia, D. Valorization of red grape (Vitis vinifera cv. Sangiovese) pomace as functional food ingredient. Ital. J. Food Sci. 2020, 32, 367-385. [CrossRef]

9. Carullo, G.; Perri, M.; Manetti, F.; Aiello, F.; Caroleo, M.C.; Cione, E. Quercetin-3-oleoyl derivatives as new GPR40 agonists: Molecular docking studies and functional evaluation. Bioorganic Med. Chem. Lett. 2019, 29, 1761-1764. [CrossRef]

10. Badolato, M.; Carullo, G.; Perri, M.; Cione, E.; Manetti, F.; Di Gioia, M.L.; Brizzi, A.; Caroleo, M.C.; Aiello, F. Quercetin/oleic acid-based G-protein-coupled receptor 40 ligands as new insulin secretion modulators. Future Med. Chem. 2017, 9, 1873-1885. [CrossRef]

11. Carullo, G.; Governa, P.; Spizzirri, U.G.; Biagi, M.; Sciubba, F.; Giorgi, G.; Loizzo, M.R.; Di Cocco, M.E.; Aiello, F.; Restuccia, D. Sangiovese cv pomace seeds extract-fortified kefir exerts anti-inflammatory activity in an in vitro model of intestinal epithelium using caco-2 cells. Antioxidants 2020, 9, 54. [CrossRef] 
12. Mildner-Szkudlarz, S.; Siger, A.; Szwengiel, A.; Bajerska, J. Natural compounds from grape by-products enhance nutritive value and reduce formation of CML in model muffins. Food Chem. 2015, 172, 78-85. [CrossRef]

13. Mildner-Szkudlarz, S.; Siger, A.; Szwengiel, A.; Przygoński, K.; Wojtowicz, E.; Zawirska-Wojtasiak, R. Phenolic compounds reduce formation of $\mathrm{N} \varepsilon$-(carboxymethyl)lysine and pyrazines formed by Maillard reactions in a model bread system. Food Chem. 2017, 231, 175-184. [CrossRef]

14. Lambert, J.D.; Lee, M.-J.; Diamond, L.; JU, J.; Hong, J.; Bose, M.; Newmark, H.L.; Yang, C.S. Short Communication dose-dependent levels of epigallocatechin-3-gallate in human colon abstract. Drug Metab. Dispos. 2006, 34, 8-11. [CrossRef]

15. Zhao, J.; Yang, J.; Xie, Y. Improvement strategies for the oral bioavailability of poorly water-soluble flavonoids: An overview. Int. J. Pharm. 2019, 570, 118642. [CrossRef]

16. Nishijima, T.; Iwai, K.; Saito, Y.; Takida, Y.; Matsue, H. Chronic ingestion of apple pectin can enhance the absorption of quercetin. J. Agric. Food Chem. 2009, 57, 2583-2587. [CrossRef]

17. Steed, J.W. The role of co-crystals in pharmaceutical design. Trends Pharmacol. Sci. 2013, 34, $185-193$. [CrossRef]

18. Spizzirri, U.G.; Carullo, G.; De Cicco, L.; Crispini, A.; Scarpelli, F.; Restuccia, D.; Aiello, F. Synthesis and characterization of a (+)-catechin and L-(+)-ascorbic acid cocrystal as a new functional ingredient for tea drinks. Heliyon 2019, 5, e02291. [CrossRef]

19. Athmouni, K.; Mkadmini Hammi, K.; El Feki, A.; Ayadi, H. Development of catechin-phospholipid complex to enhance the bioavailability and modulatory potential against cadmium-induced oxidative stress in rats liver. Arch. Physiol. Biochem. 2020, 126, 82-88. [CrossRef]

20. Karpinski, P.H. Polymorphism of active pharmaceutical ingredients. Chem. Eng. Technol. 2006, 29, $233-237$. [CrossRef]

21. Smith, G.; Bartley, J.P.; Wang, E.; Bolt, R.C. Two crystal polymorphs of a flavonoid from Melicope ellyrana. Acta Crystallogr. Sect. C Cryst. Struct. Commun. 2001, 57, 1336-1337. [CrossRef]

22. Borghetti, G.S.; Costa, I.M.; Petrovick, P.R.; Pereira, V.P.; Bassani, V.L. Characterization of different samples of quercetin in solid-state: Indication of polymorphism occurrence. Pharmazie 2006, 61, 802-804.

23. Marti, E.; Heiber, O.; Gumma, A.; Huber, G.; Utsumi, I.; Nakagawa, H.; Miyata, T.; Akimoto, K. Crystal Modifications of (+)-Catechin and Pharmaceutical Preparations Containing them. U.S. Patent US4515804A, 7 May 1985.

24. Harper, J.K.; Doebbler, J.A.; Jacques, E.; Grant, D.M.; Von Dreele, R.B. A combined solid-state NMR and synchrotron X-ray diffraction powder study on the structure of the antioxidant (+)-catechin 4.5-hydrate. J. Am. Chem. Soc. 2010, 132, 2928-2937. [CrossRef]

25. Sutsumi, H.T.; Inoshita, Y.K.; Ato, T.S.; Shizu, T.I. Configurational Studies of Complexes of Various Tea Catechins and Caffeine in Crystal State. Chem. Pharm. Bull. 2011, 59, 1008-1015. [CrossRef]

26. Griesser, U.J. The Importance of Solvates. Polymorph. Pharm. Ind. 2006, 211-233. [CrossRef]

27. Censi, R.; Di Martino, P. Polymorph impact on the bioavailability and stability of poorly soluble drugs. Molecules 2015, 20, 18759-18776. [CrossRef]

28. Xu, F.; Zhou, H.; Liu, X.; Zhang, X.; Wang, Z.; Hou, T.; Wang, J.; Qu, L.; Zhang, P.; Piao, H.; et al. Label-free cell phenotypic study of FFA4 and FFA1 and discovery of novel agonists of FFA4 from natural products. RSC Adv. 2019, 9, 15073-15083. [CrossRef]

29. Cabral, C.; Woodley, J.; Gani, R. Food waste conversion to Galactaric acid Process flowsheet. In Proceedings of the KT Consortium Annual Meeting 2017, Copenhagen, Denmark, 6-8 June 2017.

30. Carullo, G.; Durante, M.; Sciubba, F.; Restuccia, D.; Spizzirri, U.G.; Ahmed, A.; Di Cocco, M.E.; Saponara, S.; Aiello, F.; Fusi, F. Vasoactivity of Mantonico and Pecorello grape pomaces on rat aorta rings: An insight into nutraceutical development. J. Funct. Foods 2019, 57, 328-334. [CrossRef]

31. Carullo, G.; Ahmed, A.; Fusi, F.; Sciubba, F.; Di Cocco, M.E.; Restuccia, D.; Spizzirri, U.G.; Saponara, S.; Aiello, F. Vasorelaxant Effects Induced by Red Wine and Pomace Extracts of Magliocco Dolce cv. Pharmaceuticals 2020, 13, 87. [CrossRef] [PubMed]

32. Restuccia, D.; Giorgi, G.; Gianfranco Spizzirri, U.; Sciubba, F.; Capuani, G.; Rago, V.; Carullo, G.; Aiello, F. Autochthonous white grape pomaces as bioactive source for functional jams. Int. J. Food Sci. Technol. 2019, 54, 1313-1320. [CrossRef] 
33. Spizzirri, U.G.; Altimari, I.; Puoci, F.; Parisi, O.I.; Iemma, F.; Picci, N. Innovative antioxidant thermo-responsive hydrogels by radical grafting of catechin on inulin chain. Carbohydr. Polym. 2011, 84, 517-523. [CrossRef]

34. Restuccia, D.; Sicari, V.; Pellicanò, T.M.; Spizzirri, U.G.; Loizzo, M.R. The impact of cultivar on polyphenol and biogenic amine profiles in Calabrian red grapes during winemaking. Food Res. Int. 2017, 102, 303-312. [CrossRef]

35. Oliviero Rossi, C.; Caputo, P.; Loise, V.; Miriello, D.; Teltayev, B.; Angelico, R. Role of a food grade additive in the high temperature performance of modified bitumens. Colloids Surfaces A Physicochem. Eng. Asp. 2017, 532, 618-624. [CrossRef]

36. Barnes, H.A. An Introduction to Rheology, Elsevier Science, Amsterdam, 1989; Elsevier: Amsterdam, The Netherlands, 1989.

37. Caputo, P.; Shaikhah, D.; Porto, M.; Loise, V.; De Santo, M.P.; Oliviero Rossi, C. NMR Diffusiometry Spectroscopy, a Novel Technique for Monitoring the Micro-Modifications in Bitumen Ageing. Appl. Sci. 2020, 10, 5409. [CrossRef]

38. Wang, R.; Zhou, W. Stability of tea catechins in the breadmaking process. J. Agric. Food Chem. 2004, 52, 8224-8229. [CrossRef]

39. ISO. Sensory Analysis-General Guidance for the Design of Test Rooms; ISO 8589:2007; ISO: Geneva, Switzerland, 2007.

40. Carullo, G.; Sciubba, F.; Governa, P.; Mazzotta, S.; Frattaruolo, L.; Grillo, G.; Cappello, A.R.; Cravotto, G.; Di Cocco, M.E.; Aiello, F. Mantonico and pecorello grape seed extracts: Chemical characterization and evaluation of in vitro wound-healing and anti-inflammatory activities. Pharmaceuticals 2020, 13, 97. [CrossRef]

41. Chadha, R.; Bhandari, S. Drug-excipient compatibility screening-Role of thermoanalytical and spectroscopic techniques. J. Pharm. Biomed. Anal. 2014, 87, 82-97. [CrossRef]

42. Lima, D.B.; Gondim, N.; Denise, P.B.L.; Tu, F.N.R. Compatibility study between hydroquinone and the excipients used in semi-solid pharmaceutical forms by thermal and non- thermal techniques. J. Therm. Anal. Calorim. 2015, 719-732. [CrossRef]

43. Yahfoufi, N.; Alsadi, N.; Jambi, M.; Matar, C. The immunomodulatory and anti-inflammatory role of polyphenols. Nutrients 2018, 10, 1618. [CrossRef]

44. Carocho, M.; Morales, P.; Ferreira, I.C.F.R. Antioxidants: Reviewing the chemistry, food applications, legislation and role as preservatives. Trends Food Sci. Technol. 2018, 71, 107-120. [CrossRef]

45. Coppola, L.; Gianferri, R.; Oliviero, C.; Nicotera, I. Solution and liquid crystalline microstructures in sodium taurodeoxycholate/D2O mixtures. Langmuir 2003, 19, 1990-1999. [CrossRef]

46. Baldino, N.; Gabriele, D.; Lupi, F.R.; Oliviero Rossi, C.; Caputo, P.; Falvo, T. Rheological effects on bitumen of polyphosphoric acid (PPA) addition. Constr. Build. Mater. 2013, 40, 397-404. [CrossRef]

47. Oliviero, C.; Coppola, L.; La Mesa, C.; Ranieri, G.A.; Terenzi, M. Gemini surfactant-water mixtures: Some physical-chemical properties. Colloids Surfaces A Physicochem. Eng. Asp. 2002, 201, 247-260. [CrossRef]

48. Su, Y.L.; Leung, L.K.; Huang, Y.; Chen, Z.Y. Stability of tea theaflavins and catechins. Food Chem. 2003, 83, 189-195. [CrossRef]

49. Seto, R.; Nakamura, H.; Nanjo, F.; Hara, Y. Preparation of Epimers of Tea Catechins by Heat Treatment. Biosci. Biotechnol. Biochem. 1997, 61, 1434-1439. [CrossRef]

50. Aranibar, C.; Aguirre, A.; Borneo, R. Utilization of a by-product of chia oil extraction as a potential source for value addition in wheat muffins. J. Food Sci. Technol. 2019, 56, 4189-4197. [CrossRef]

51. Topkaya, C.; Isik, F. Effects of pomegranate peel supplementation on chemical, physical, and nutritional properties of muffin cakes. J. Food Process. Preserv. 2019, 43, e13868. [CrossRef]

52. Figoli, A.; Marino, T.; Galiano, F.; Blasi, E.; Belsito, E.L.; Liguori, A.; Leggio, A.; Rombolà, L.; Morrone, L.A. Potentiality of polymeric membranes in aromatherapy: Application to bergamot essential oil. Sep. Purif. Technol. 2018, 207, 166-178. [CrossRef]

53. Arthur, C.L.; Pawliszyn, J. Solid Phase Microextraction with Thermal Desorption Using Fused Silica Optical Fibers. Anal. Chem. 1990, 62, 2145-2148. [CrossRef]

54. Leggio, A.; Leotta, V.; Belsito, E.L.; Di Gioia, M.L.; Romio, E.; Santoro, I.; Taverna, D.; Sindona, G.; Liguori, A. Aromatherapy: Composition of the gaseous phase at equilibrium with liquid bergamot essential oil. Chem. Cent. J. 2017, 11, 111. [CrossRef] 
55. Belsito, E.L.; Carbone, C.; Di Gioia, M.L.; Leggio, A.; Liguori, A.; Perri, F.; Siciliano, C.; Viscomi, M.C. Comparison of the volatile constituents in cold-pressed bergamot oil and a volatile oil isolated by vacuum distillation. J. Agric. Food Chem. 2007, 55, 7847-7851. [CrossRef]

56. Whitfield, F.B.; Mottram, D.S. Critical reviews in food science and nutrition volatiles from interactions of maillard reactions and lipids volatiles from interactions of maillard reactions and lipids. Crit. Rev. Food Sci. Nutr. 1992, 31, 1-58. [CrossRef]

57. Rizzi, G.P. Formation of Pyrazines from Acyloin Precursors under Mild Conditions. J. Agric. Food Chem. 1988, 36, 349-352. [CrossRef]

58. Vernin, G.P. Mechanisms of formation of heterocyclic compounds in Maillard and pyrolysis reactions. In Chemistry of Heterocyclic Compounds in Flavours and Aromas; Vernin, G., Ed.; Chemistry of Heterocyclic Compounds in Flavours and Aromas: Chichester, UK, 1982; pp. 151-207.

59. Poinot, P.; Arvisenet, G.; Grua-Priol, J.; Colas, D.; Fillonneau, C.; Le Bail, A.; Prost, C. Influence of formulation and process on the aromatic profile and physical characteristics of bread. J. Cereal Sci. 2008, 48, 686-697. [CrossRef]

60. Dong, X.; Hu, X.; Sun, L.; Zhang, H.; Wu, L.; Wang, B. Volatile Compounds of Wheat Flour and Steamed Bread as Affected by Wheat Storage Time. SM Anal. Bioanal. Tech. 2018, 3, 2015. [CrossRef]

61. Birch, A.N.; Petersen, M.A.; Hansen, Å.S. Aroma of wheat bread crumb. Cereal Chem. 2014, 91, 105-114. [CrossRef]

Publisher's Note: MDPI stays neutral with regard to jurisdictional claims in published maps and institutional affiliations. 